\title{
Self-care and Wellness Needs Growing Amid Pandemic for Latina and Black Women Age 50+
}

Latina and Black women age 50+ experiencing the stress of the pandemic are placing a renewed emphasis on inner health, self-care, and well-being.

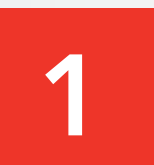

Since the pandemic began, a majority of Latina and Black women age 50+ are focusing more on health and well-being.

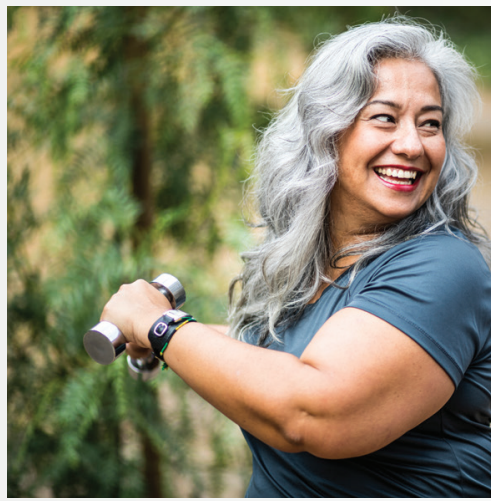

Health > Appearance

\section{$63 \%$}

of both Latina and Black women age 50+ have focused more on health than their appearance during the pandemic.

Inner Peace > Outer Beauty

$60 \%$ of Latinas $50+$

have focused more on inner peace than outer beauty.

$58 \%$ of Black women $50+$ have focused more on inner peace than outer beauty.

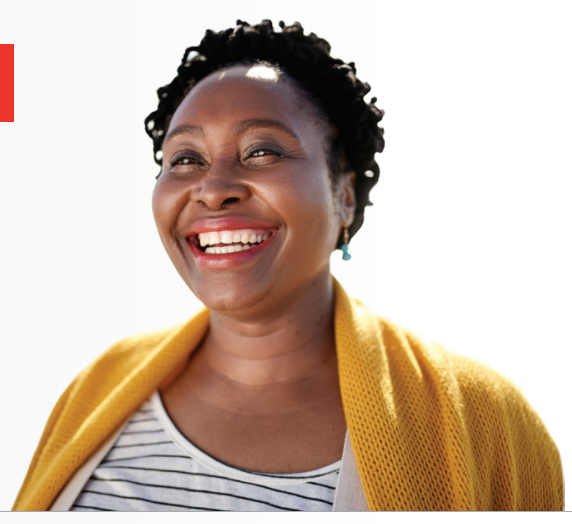

Source: Mirror/Mirror: AARP Survey of Black Women's Reflections on Beauty, Age, and Media (2021); Latinas and Beauty as We Age: A Cultural Reflection (2021)

Contacts: Colette Thayer, Ph.D. | cthayer@aarp.org. Angela Houghton | ahoughton@aarp.org.

Media inquiries: media@aarp.org. https://doi.org/10.26419/res.00429.007 www.aarp.org/wellbeing

The pandemic has taken its toll on

2 Latina and Black women age $\mathbf{5 0 +}$ emotionally and physically.

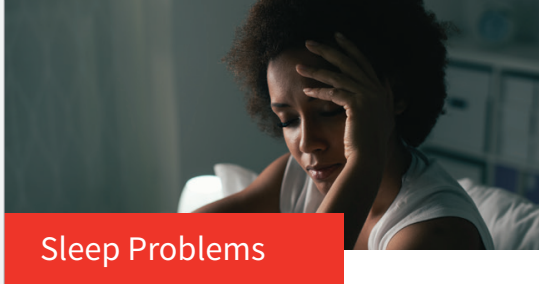

$63 \%$ of Latinas $50+$

have had problems sleeping since the pandemic began.

$49 \%$ of Black women $50+$ have had problems with sleep since the pandemic began.

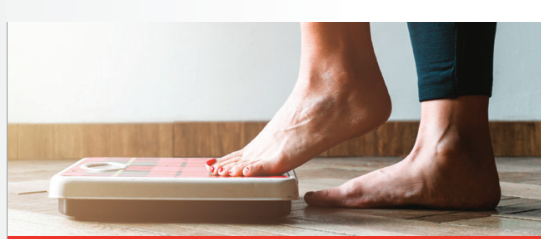

Problems with weight/eating

$69 \%$ of Latinas $50+$

have experienced issues with weight or eating since the pandemic began.

$62 \%$ of Black women $50+$

have experienced issues with weight or eating since the pandemic began.

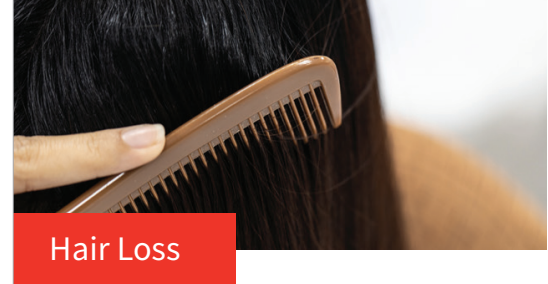

$29 \%$ of Latinas $50+$

have experienced hair loss or thinning during the pandemic.

$19 \%$ of Black women 50+ have experienced hair loss or thinning during the pandemic.

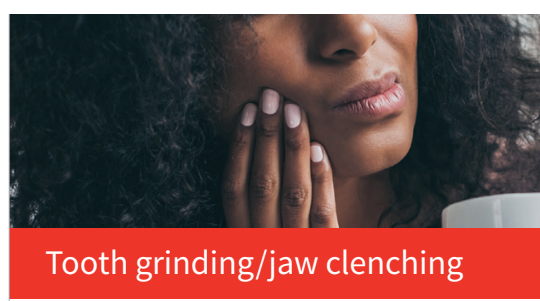

$\mathbf{2 7} \%$ of Latinas $50+$

have experienced tooth grinding or jaw clenching during the pandemic

$11 \%$ of Black women $50+$ have experienced tooth grinding or jaw clenching during the pandemic. 